\title{
Abandonment of Learners MOOC Problematic Analysis and Proposed Solutions
}

\author{
Yassine Ahmed Chakor \\ Network Computing Modeling and E-learning \\ Avenue Ibn Sina, Rabat 10000, Maroc \\ Ecole Mohammadia d'Ingénieurs
}

\author{
Nour-eddine El Faddouli \\ Network Computing Modeling and E-learning \\ Avenue Ibn Sina, Rabat 10000, Maroc \\ Ecole Mohammadia d'Ingénieurs
}

\begin{abstract}
The E-learning is booming and growing strongly. However, the dropout rate in the E-learning courses is still very high particularly for the MOOC. Several reasons push the learners to quit the distance learning programs and this cause them failure during the learning process.

In this work, the causes and effects behind the abandonment of distance learning will be determinate by representing them in a problem tree then we'll propose some solutions as objectives to realize and minimize the dropout rate of the distance learning.
\end{abstract}

\section{Keywords}

MOOC, Abandon, Tutor, Learner, Distance learning

\section{INTRODUCTION}

We The rivalry that exists worldwide across multiple platforms and efforts deployed by training institutions to take position (a good position) in this sector urge them to opt for excellence and offer adequate solution that is capable to seduce and attract learners. Nevertheless, these are priori judgments on the shape and a posteriori on the bottom and on the level of assistance.

It is insufficient to offer a good content and a good program, but it's necessary to consider the aspect of learner relationship management LRM. Beyond a simple assistance, we should anticipate the eventual abandonment of the learner.

\section{PROBLEMATIC AND ISSUES}

All Most of E-learning training platforms including those created and launched by major universities undergo a very high rate of abandonment, which gradually manifest itself during the programming period of a course. This is particularly true for the MOOC because it is about online massive courses that are open without a prior selection. We notice that even in the middle of an E-learning program, more than half of registered learners throw in the towel. According to the last study conducted by EDX proves that only $17 \%$ of the registered learners have consulted the courses and $8 \%$ had a certificate that validates the end of the MOOCs (John Hennessy 2016) [1]. And only a low percentage can boast a good attendance and behavior in terms of participation and production.

The challenge is to reduce the abandonment rate of the distance learning programs with the aim to develop the learners' knowledge and competence. The risk is to see that distance learning can only work under an authoritarian system and very little in a free space.

The dropout rate can harm the reputation of an E-Learning platform and even the image of the institution that is in charge of it.
To give the distance learning the place it deserves; we must seriously address the problem of the dropout and see how to face it. Or even how to anticipate it by detecting its premises and implementing a process that will reduce or exclude it. Several roles have been identified around the good functioning of a distance learning program (educator, tutor, technical team...) we think that we should add a new role (or even a new actor) the mediator.

\section{METHOD}

To classify the reasons that push a learner to abandon an Elearning program and to schematize it a problem tree and a solution tree will be used. Which will provides an overview of all the known causes and effects to this problem.

\subsection{Problem tree}

Let's start by searching the principal causes that push a learner to abandon distance learning.

In this figure the causes of the learner's dropout to an ELearning program are determinate:

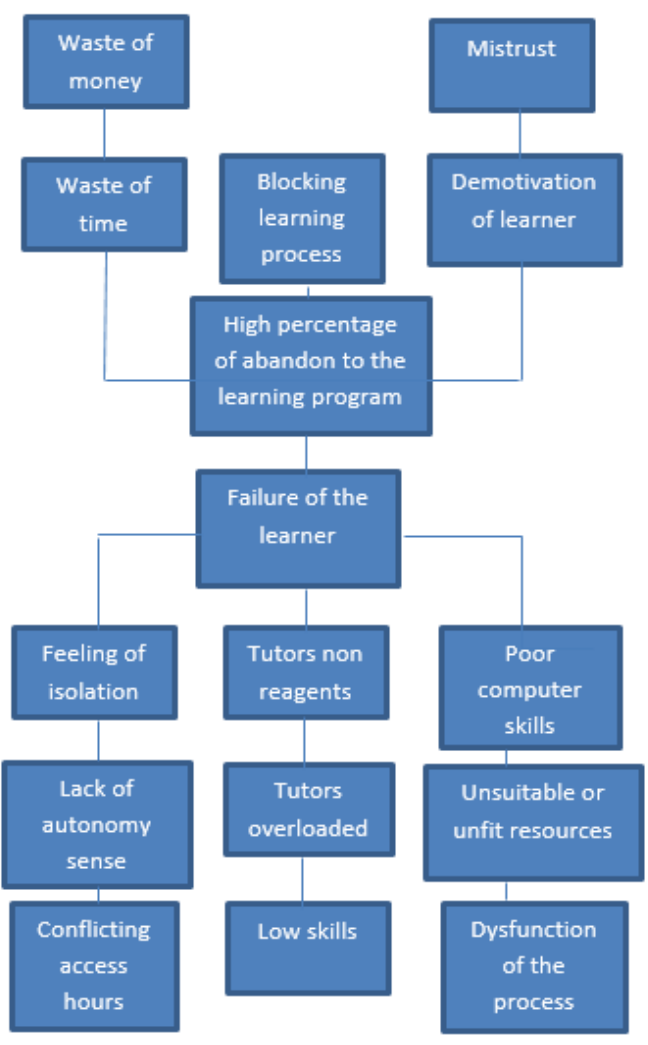

Figure 1 : Problem tree 
Among the effects of this problem are the waste of money and time, which are factors we endeavor to solve by creating digital campuses and online learning programs. These generate the learner a lack of self-confidence and a demotivation and thus a blockage in the learning process.

Those causes are categorized accordingly:

Socio-cognitive: various researchers and educators have spoken about problems due to the sense of isolation that the learner feels during the learning period when he/she faces their device (Licoppe, 2007) [2], this has a big negative impact on the socio affective of the learner. For this reason, the learner must be independent and responsible for his/her actions so that he/she can confront this feeling.

Another problem is that tutors have a lot of duties (ex a tutor who has to meet the specific needs of hundreds of learners while he does not have enough time to answer all of them) which, therefore, hinders the tutor's reaction. (Clément Dussarps), [3] «L'abandon en formation à distance », Distances et médiations des savoirs [En ligne], $10 \mid 2015$, mis en ligne le 17 juin 2015, consulté le 01 mars 2016. URL: http://dms.revues.org/1039). Or access times are not well-scheduled or inadequate because most of students are employees and therefore generally available only in the evenings or during the weekends.

Technical issues: So as to have a good online training, we must ensure that all learning facilities are available to the learners and that the tutors do not block the learning process.

The learning platform may have blockages due to the content overload, a problem in the database or an update that requires an intervention of an internal technical team in the shortest delay.

Technical means adapted to support the platforms that evolve day by day with the evolution of the information technologies, which cause a big trouble because not all the learners have the ability to purchase such a devices with special characteristics that allow an easy access to those resources and courses.

Level Problems: tutors' incompetence in the educational field or low computer skills can generate a dysfunction of the learning process. (Dussarps, 2015). [4]

Unsuitable or insufficient resources shared in the platforms, due to the lack of tutors' experience in this field, which is new for them. Because Tutors used to give lessons to students and not to publish courses according to everyone's needs.

On the side of the learner, we also find weak knowledge in the manipulation of the available distance learning tools (Licoppe, 2007 Hermès (Paris.1988) [5] [ISSN 0767-9513], 2007, N 47; p. 59-67 04/2009) and (Evaluation du dispositif d'Enseignement à Distance à l'Université de Strasbourg March 2012 Marc Trestini and Ecaterina Pacurar).

\subsection{Objective/Solution tree:}

In order to face the learner's failure during the distance learning, we have adopted a number of objectives with ultimate aim to minimize the dropout rate.

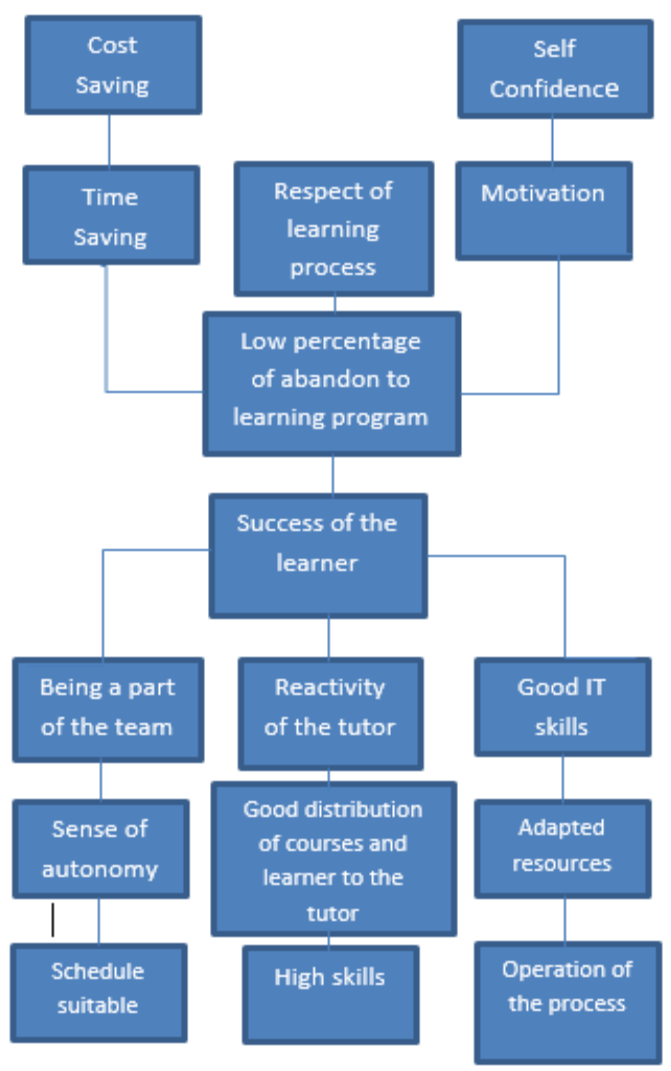

Figure 2 : Objective/Solution tree

Socio-cognitive: For the purpose of preventing the learner from not falling of what is called the sense of isolation, we should make him/her feel that they belong to a group or a team like in a real classroom. That is to say when the course session is scheduled; all students must appear online and form group discussion between learners and tutors in real time allowing, therefore, the exchange of information to take place. As a result, tutors will be enabled to make the correction of exercises respecting the course hours that are not flexible and for this we will try to adapt and classify them into groups based on their availability.

Level Problems: Technically, tutors need also a training to better use the learning interfaces so that they can react, or even give tutors a pedagogical training because orientating a learner online differs from doing it in an actual course.

Speaking also about the content that is not well-distributed according to the special needs of each learner and competences (adaptation and content personalization) since what the learner wants to achieve is not aligned with those skills (Florian Clerc, Marie Lefevre, Nathalie Guin, JeanCharles Marty. [6])

Resources should be adapted to the course (what requires practical work must be accompanied with complementary exercises, videos...).

Technical issues: To have a good online learning program we must ensure that the technical means are adapted to support the platforms that evolve exponentially.

The learning platform must have a technical support to maintain these resources and not to block the learning process, and solve problems due to bottlenecks and overload of content on the database. A group of technicians and engineers is essential, and must be available to ensure the continuity of the 
process, as it should engage with experts in this field, who are knowledgeable in terms of the online publication of courses because tutors are not always capable to carry out several tasks. Therefore, a good distribution of shares and roles is crucial so as to avoid that the student abandons online learning.

If these criteria were implemented, the result would have been favorable and students would not have abandoned the MOOCs.

\section{SYNTHESIS}

In recent years, researchers have proposed several solutions to make the distance learning successful and that the outcomes would be achieved but most of them have opted for the personalization of the learner's courses and study his/her behavior....

Nevertheless, the major problem is the abandonment of distance learning who can be considered as a special case of failure or one of its possible consequences (Ewusi-Mensah et Przasnyski, 1995) [7].

To reach our objectives:

Develop a method to create a smarter solution that can integrate a platform of distance learning especially MOOC to identify profiles of susceptible persons:

- Persons able to continue the MOOC learning until the end.

- Persons who require support to continue the MOOC.

- Person who don't follow the criteria for distance learning.

In our next researches the classes of learners whose risk of abandonment is very important, somewhat important or inexistent will be identified.

\section{CONCLUSION}

The MOOCs underwent a revolution in recent years; many universities have opted for this solution. Published research often speak of the large number of learners enrolled in these courses; however, they do not raise the point that few learners were satisfied and that the results are poor, or most learners drop courses.
This paper presented the different causes and effects of the abandonment in order to analyze the root cause of the problem and propose solutions that could decrease the dropout rate or eliminate it completely.

\section{REFERENCES}

[1] Lesca Nicolas, CARON-FASAN Marie-Laurence, «Facteurs d'échec et d'abandon d'un projet de veille stratégique : retours d'expériences. », Systèmes d'information \& management 3/2008 (Volume 13) p. 17-42 URL : www.cairn.info/revue-systemes-dinformation-et-management-2008-3-page-17.htm. DOI : 10.3917/sim.083.0017.

[2] http://www.cairn.info/revue-systemes-d-information-etmanagement-2008-3-page-17.htm

[3] (Clément Dussarps, «L'abandon en formation à distance »,Distances et médiations des savoirs [En ligne], $10 \mid 2015$, mis en ligne le 17 juin 2015, consulté le 01 mars 2016. URL: http://dms.revues.org/1039)

[4] (Licoppe, 2007 Hermès (Paris.1988) [ISSN 0767-9513], 2007, $\mathrm{N}^{\circ} 47$; p. 59-67 04/2009) and (Evaluation du dispositif d'Enseignement à Distance à l'Université de Strasbourg March 2012 Marc Trestini and Ecaterina Pacurar).

[5] http://www.cairn.info/revue-distances-et-savoirs-2007-4page-547.htm Ayachi-Ghannouchi Sonia, ChenitiBelcadhi Lilia, «Expérience de tutorat dans le cadre d'un enseignement à distance. Témoignage et enseignements tirés», Distances et savoirs 4/2007 (Vol. 5) , p. 547557 URL : www.cairn.info/revue-distances-et-savoirs2007-4-page-547.htm. DOI : 10.3166/ds.5.547-557.

[6] (Florian Clerc, Marie Lefevre, Nathalie Guin, JeanCharles Marty. Mise en place de la personnalisation dans le cadre des MOOCs. 7`eme Conf'erence sur les Environnements Informatiques pour l'Apprentissage Humain - EIAH'2015, Jun 2015, Agadir, Maroc. 2015.)

[7] John Hennessy (Stanford) : "Les Mooc ne fonctionnent pas comme prévu initialement (http://www.letudiant.fr/educpros/actualite/etats-unis-ouen-sont-les-mooc.html) Marine Miller | Publié le 03.03 .2016 